\title{
Recent advances in managing tricuspid regurgitation [version
}

\section{1; peer review: 3 approved]}

\author{
Benedetto Del Forno (D1), Elisabetta Lapenna1, Malcom Dalrymple-Hay2, \\ Maurizio Taramasso ${ }^{3}$, Alessandro Castiglioni ${ }^{1}$, Ottavio Alfieri ${ }^{1}$, Michele De Bonis ${ }^{1}$ \\ ${ }^{1}$ IRCCS San Raffaele Hospital, Milan, Italy \\ 2Plymouth Hospitals NHS Trust, Department of Cardiac Surgery, Derriford Hospital, Plymouth, UK \\ ${ }^{3}$ UniversitätsSpital Zurich, University Heart Center, Zurich, Switzerland
}

V1 First published: 22 Mar 2018, 7(F1000 Faculty Rev):355

https://doi.org/10.12688/f1000research.13328.1

Latest published: 22 Mar 2018, 7(F1000 Faculty Rev):355

https://doi.org/10.12688/f1000research.13328.1

\section{Abstract}

Isolated tricuspid valve surgery is usually carried out with very high morbidity and mortality given the complexity of the affected patients. In light of this, trans-catheter tricuspid valve interventions have been emerging as an attractive alternative to surgery over the last few years. Although feasibility has been shown with a number of devices, clinical experience remains preliminary and associated with significant clinical and technical challenges. Here we describe currently available trans-catheter treatment options for severe tricuspid regurgitation implanted in different locations.

\section{Keywords}

Tricuspid valve repair, percutaneous, trans-catheter

\section{Open Peer Review \\ Approval Status \\ 12 \\ 3 \\ version 1 \\ 22 Mar 2018 \\ Faculty Reviews are review articles written by the prestigious Members of Faculty Opinions. The articles are commissioned and peer reviewed before publication to ensure that the final, published version is comprehensive and accessible. The reviewers who approved the final version are listed with their names and affiliations.}

1. Gianfranco Butera, IRCCS Policlinico San Donato, San Donato Milanese, Italy

2. Meindert Palmen, Leiden University Medical Center, Leiden, The Netherlands

3. Luigi Paolo Badano, University of Padua,

Padua, Italy

Any comments on the article can be found at the end of the article. 
Corresponding author: Benedetto Del Forno (delforno.benedetto@hsr.it)

Author roles: Del Forno B: Writing - Original Draft Preparation; Lapenna E: Formal Analysis; Dalrymple-Hay M: Writing - Review \& Editing; Taramasso M: Writing - Review \& Editing; Castiglioni A: Formal Analysis; Alfieri O: Supervision; De Bonis M: Supervision

Competing interests: No competing interests were disclosed.

Grant information: The author(s) declared that no grants were involved in supporting this work.

Copyright: @ 2018 Del Forno B et al. This is an open access article distributed under the terms of the Creative Commons Attribution License, which permits unrestricted use, distribution, and reproduction in any medium, provided the original work is properly cited.

How to cite this article: Del Forno $B$, Lapenna $E$, Dalrymple-Hay $M$ et al. Recent advances in managing tricuspid regurgitation [version 1; peer review: 3 approved] F1000Research 2018, 7(F1000 Faculty Rev):355 https://doi.org/10.12688/f1000research.13328.1

First published: 22 Mar 2018, 7(F1000 Faculty Rev):355 https://doi.org/10.12688/f1000research.13328.1 


\section{Introduction}

Tricuspid valve insufficiency is reported as the most common valvular heart disease, affecting 65 to $85 \%$ of the population ${ }^{1}$; the true prevalence of moderate or severe tricuspid regurgitation (TR) has been estimated at 1.6 million people in the United States $^{2}$. Despite this prevalence and its known association with mortality ${ }^{3}$, the tricuspid was considered as the "forgotten valve" until recently for two main reasons. Firstly, symptoms resulting from TR may be uncertain, particularly in the early stages of the disease, leading to a late referral. Secondly, once right ventricular dysfunction develops, the patient is considered end-stage. Moreover, functional TR frequently coexists with left-sided valve disease (LVD), but avoidance of concomitant tricuspid valve repair was accepted based on the incorrect assumption that TR would improve once the primary LVD had been treated ${ }^{4}$.

When untreated, TR commonly progresses to right ventricular failure, with the associated impact on the patient's prognosis and quality of life. In the subgroup with advanced disease, the indication for treatment remains more challenging given the complexity of the patients and the significant risk of 30-day mortality ${ }^{5}$.

Recently, the assessment and management of tricuspid valve disease have developed because of the increasing body of evidence regarding the adverse impact of severe TR and the recent advances in surgical and percutaneous trans-catheter techniques. In the current European guidelines, the indication for surgery for severe TR is now generally accepted (class I). With regard to treatment in lesser degrees of TR, there is a trend for intervention, especially during surgery for left heart valve disease and/or in cases of significant dilatation of the tricuspid annulus (class IIa). In addition, after previous left-sided valve surgery and in the absence of recurrent left-sided valve dysfunction, surgery may be considered in patients with severe TR who are symptomatic or have progressive right ventricular dilatation/dysfunction in the absence of severe right ventricular or left ventricular dysfunction and/or severe pulmonary vascular disease/hypertension ${ }^{6}$. This more aggressive approach to TR after previous left-sided valve surgery may result in dealing with fewer end-stage patients who could benefit from the treatment.

Despite recent progress in the understanding of this complex pathology and the attempt to treat these patients at the earliest possible stage, the majority remain a high-risk population affected by severe TR, right ventricular dysfunction, and multiple comorbidities. In view of the above, different trans-catheter tricuspid valve therapies are emerging.

\section{Challenging anatomical features for trans-catheter therapies}

The anatomy of the tricuspid valve apparatus appears to be more complex than the mitral valve. It is variable in terms of number, size, and attachment of the papillary muscle and, in contrast to the mitral valve, tricuspid valve chordae may attach directly to the right ventricular endocardium.
The tricuspid annulus is an ellipsoid nonplanar structure with a saddle-shaped conformation that becomes more circular as it dilates in an anterior-posterior direction in response to right ventricular enlargement, which is also a dynamic structure that modifies its dimension and shape during the cardiac cycle?

Several aspects represent a challenge for percutaneous therapy. The tricuspid orifice is larger, more triangular, and more fragile than the mitral one; in addition, the lack of calcium observed in secondary TR represents an anchorage-complicating factor.

The tricuspid annulus has significant anatomical relationships with the right coronary artery, the coronary sinus, the aortic valve, and the atrio-ventricular node. All of these structures can be damaged during trans-catheter procedures.

The angulation between both venae cavae and the tricuspid annulus should be taken into consideration in the conception of a delivery system for percutaneous approach; alternatively, if considering a trans-apical approach, the thin apical wall and the presence of multiple chordae render this approach very difficult ${ }^{8}$.

Finally, in a considerable portion of patients, the secondary TR is due to the presence of pacemaker or defibrillator leads ${ }^{9}$ that represent a limitation in applying percutaneous techniques.

\section{Multi-modal imaging to plan trans-catheter therapies} Quantification of the severity of TR has been well described by the European Association of Echocardiography guidelines, clearly defining qualitative and quantitative parameters ${ }^{10}$. Moreover, considering the last guidelines of the European Society of Cardiology, the measurement of the septo-lateral dimension of the tricuspid annulus to identify significant annular dilatation (diastolic dimension $\geq 40 \mathrm{~mm}$ or $>21 \mathrm{~mm} / \mathrm{m}^{2}$ ) is important, as it supports intervention ${ }^{11}$.

To perform a first evaluation, a trans-thoracic echocardiogram is enough, but, to correctly plan a percutaneous intervention, a multi-modal imaging approach is mandatory. Three-dimensional trans-esophageal echocardiogram has significantly improved the accuracy of tricuspid valve apparatus imaging, giving adjunctive information on its anatomic components and highlighting the lesions liable for the mechanism of regurgitation. A standardization of imaging projections has been proposed by Lang et al. ${ }^{12}$ to obtain an en face view of the tricuspid valve, improving communication with the interventionist.

Pre-procedural planning using multi-detector computed tomography (MDCT) provides many details regarding tricuspid annulus measurement, the relationship with the surrounding structures, and good-quality motion-free images of the right ventricular outflow tracts ${ }^{13}$. Furthermore, MDCT is used to access routes for percutaneous procedures.

Applying this multi-modal imaging approach is crucial to obtain essential information to correctly choose the proper trans-catheter technique. 
Trans-catheter therapies for tricuspid regurgitation

Given the considerable surgical risk of tricuspid valve surgery for severe TR, especially in the reoperation scenario, there has been a progressive development of percutaneous trans-catheter techniques in the last few years. Anatomical aspects, such as the non-planar and large tricuspid annulus, absence of calcium, right ventricular geometry, and approximation of critical surrounding structures, have to be taken into consideration and make this procedure very challenging ${ }^{14}$.

The Gate ${ }^{\mathrm{TM}}$ Tricuspid Valved Stent (Navigate Cardiac Structure Inc.) is the first prosthesis implanted in the tricuspid position using a trans-jugular or trans-atrial mode of access and has been implanted successfully in two patients ${ }^{15}$. As an alternative to trans-catheter tricuspid valve implantation, four kinds of percutaneous therapies have recently emerged to treat severe tricuspid valve regurgitation: trans-catheter heterotopic implant of valve into the vena cava, trans-catheter annuloplasty, trans-catheter edge-to-edge repair, and trans-catheter implant of a device dedicated to improve leaflet coaptation.

\section{Heterotopic caval trans-catheter valve implantation}

Caval valve implantation (CAVI) has been proposed to address the reflux of severe TR into both venae with the purpose of effectively improving the symptoms of right ventricular failure. The main anatomical challenges in applying this specific technique is the large and variable diameter of the inferior and superior vena cava, especially in the presence of chronic severe TR, and the length of the landing zone with respect to the inferior vena cava (IVC) and the closeness to the hepatic veins.

Clinical experience started in 2011, with the first reported compassionate case of CAVI using two custom-made self-expandable valves ${ }^{16}$. Since then, compassionate cases confirmed the feasibility of this technique and the immediate hemodynamic improvement ${ }^{17}$. In light of this, two valve prototypes, the selfexpandable TricValve $(\mathrm{P}+\mathrm{F}$ Products + Features Vertriebs $\mathrm{GmbH}$, Vienna, Austria, in cooperation with Braile Biomedica, São José do Rio Preto, Brazil) and the balloon-expandable Edwards valve (Edwards Lifesciences, Irvine, CA, USA), have been tested in proof-of-concept trials.

The TricValve consists of two self-expandable bioprosthetic valves covering sizes from 28 to $43 \mathrm{~mm}$ for both caval veins. This device does not require pre-stenting of the cavae to permit its implant. The prosthetic valve conceived for the IVC has the upper segment protruding into the right atrium to avoid any dangerous interaction with hepatic veins. The device designed for the superior vena cava is mounted on a funnel-shaped stent frame to allow its release at the level of the cavo-atrial junction. The procedure is guided by fluoroscopy, and echocardiography is used for post-interventional control.

Concerning the heterotopic caval implantation of $29 \mathrm{~mm}$ balloon-expandable Edwards SAPIEN XT or SAPIEN 3 valves, it has been performed off-label for patients at prohibitive surgery risk. To consider a safe implantation of this prosthesis, a self-expandable stent was implanted at the level of the cavo-atrial junction to create a landing zone for valve anchoring. Ten compassionate cases have been performed, but, although the implant was successfully achieved in all patients without peri-procedural complications, the 9-month follow-up mortality was $90 \%{ }^{18}$.

\section{Trans-catheter tricuspid valve annuloplasty}

Severe functional TR is due to a significant annular dilatation, and that is why surgical annuloplasty is the first procedure of choice in treating this condition. Applying this principle to the percutaneous techniques results in several complexities. Unlike its left counterpart, the tricuspid annulus is not prominent or fibrous and for this reason does not ensure proper stability for safely anchoring some devices. Moreover, the highly individual shape of the valve adds complexity. Finally, several crucial structures are closely related to the tricuspid annulus and are at risk of injury.

The Trialign device (Mitralign, Inc. Tewksbury, MA, USA) mimics the Kay surgical procedure consisting of plication of the tricuspid annulus at the level of the posterior leaflet ${ }^{19}$. The operator performs a trans-catheter bicuspidization of the tricuspid valve through a trans-venous jugular approach, implanting one or multiple pairs of pledgets. Once implanted, the pledgeted sutures are brought together to obtain plication of the annulus. The first-in-human experience with this system has been reported, demonstrating the feasibility of this procedure and resulting in a reduction of the tricuspid annular dimensions ${ }^{20}$.

The safety and feasibility of this device has been tested in the SCOUT I feasibility trial, which included 15 patients with severe TR who underwent tricuspid annuloplasty with the Trialign. The device was successfully implanted in all cases, with only one procedural complication (new right coronary stenosis requiring coronary stenting). At 30-day follow-up, survival was $100 \%$, with a technical success rate of $80 \%$ (three single pledget dehiscence). No major adverse events were observed. A significant reduction in the tricuspid annular area, as well as an improvement in functional class and quality of life, was maintained for up to 6 months ${ }^{21}$.

The TriCinch system (4Tech Cardio, Galway, Ireland) is a percutaneous annuloplasty device designed to cinch the tricuspid annulus, improving leaflet coaptation and reducing $\mathrm{TR}^{22}$. Through a transfemoral mode of access, a corkscrew element is implanted in the anterior tricuspid annulus. Once the corkscrew is secured, the system is retrieved and a self-expandable nitinol stent is introduced over the wire and coupled to the implant. The whole system is then tensioned to reshape the tricuspid valve and to increase the leaflet coaptation under live echo guidance. Finally, the stent is deployed in the IVC to maintain the tension applied. The first-in-human implantation of this device has been reported ${ }^{23}$. The device is currently being evaluated in an ongoing feasibility trial, the PREVENT study (Percutaneous Treatment of Tricuspid Valve Regurgitation with the TriCinch System; NCT02098200) with the purpose of demonstrating immediate and post-operative safety and 
efficacy in TR reduction ( $\geq 1$ grade) in 24 patients. A secondgeneration device with improved durability is currently under preliminary clinical evaluation. The first-in-man patient has been recently successfully treated ${ }^{24}$.

The Cardioband system (Edwards Lifescience, Irvine, CA, USA) is a suture-less and adjustable surgical-like Dacron band that mimics the effects of undersized annuloplasty (Figure 1). It consists of a three-step approach: implant deployment, anchor implantation, and size adjustment. A percutaneous transfemoral approach is used and the device is implanted on the atrial side of the tricuspid annulus by means of multiple anchor elements. After the implant, the size of the device can be reduced in a reversible fashion in order to reduce the annular dimension and increase leaflet coaptation. Preliminary results from the early feasibility trial in the tricuspid position have been recently presented ${ }^{25}$. Among 20 patients with severe functional TR treated so far, a $27 \%$ reduction of septo-lateral tricuspid annular dimension has been reported. At 30 days, core-lab adjudicated data (available for a minority of patients) showed a reduction of $\mathrm{TR}$, with a significant improvement in symptoms and quality of life.

The Millipede system (Millipede, LLC, Ann Arbor, MI, USA) is a fully repositionable and retrievable complete ring, which can be implanted surgically or in a trans-catheter fashion on the atrial side of the native tricuspid annulus in order to restore its shape and diameter. So far, only two patients have received a tricuspid implant under direct surgical vision, showing tricuspid diameter reductions of $42-45 \%$, with no post-procedural residual $\mathrm{TR}^{26}$

Trans-catheter edge-to-edge repair

The MitraClip® device (Abbott Vascular, Santa Clara, CA, USA) consists of a $4 \mathrm{~mm}$ wide cobalt-chromium, polyestercovered implant with two arms that are opened and closed by control mechanisms on the clip delivery system (Figure 2). During the last few years, the MitraClip ${ }^{\circledR}$ has become an attractive trans-catheter alternative to treat selected patients affected by severe mitral regurgitation and recently has been used successfully for treating severe TR in very high-risk patients $^{27}$. The transfemoral access has become the preferred route of access today. Nickenig et al. recently reported promising 30-day outcomes in a series of 64 high-risk patients with severe functional TR treated with tricuspid clipping. A significant reduction in TR and clinical improvements were observed $^{28}$.

\section{Coaptation device}

The FORMA Repair System (Edwards Lifesciences, Irvine, CA, USA) acts as a coaptation device with the purpose of reducing the TR grade in patients with severe TR. It is composed of a spacer, which is positioned into the regurgitant orifice, creating a platform for the native leaflet to coapt, and a rail anchored at the right ventricular apex, which ensures device fixation. The spacer consists of a foam-filled polymer balloon available in two sizes (12 and $15 \mathrm{~mm}$ ). Introduced through venous subclavian access, after the final positioning, it is proximally

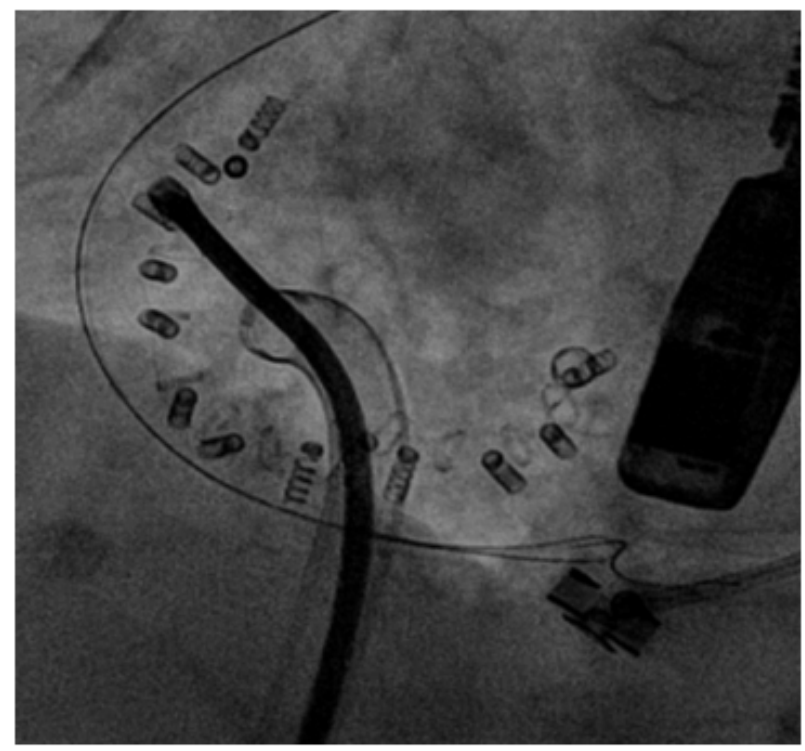

Figure 1. Intra-procedural imaging of the Cardioband system (Edwards Lifescience, Irvine, CA, USA).

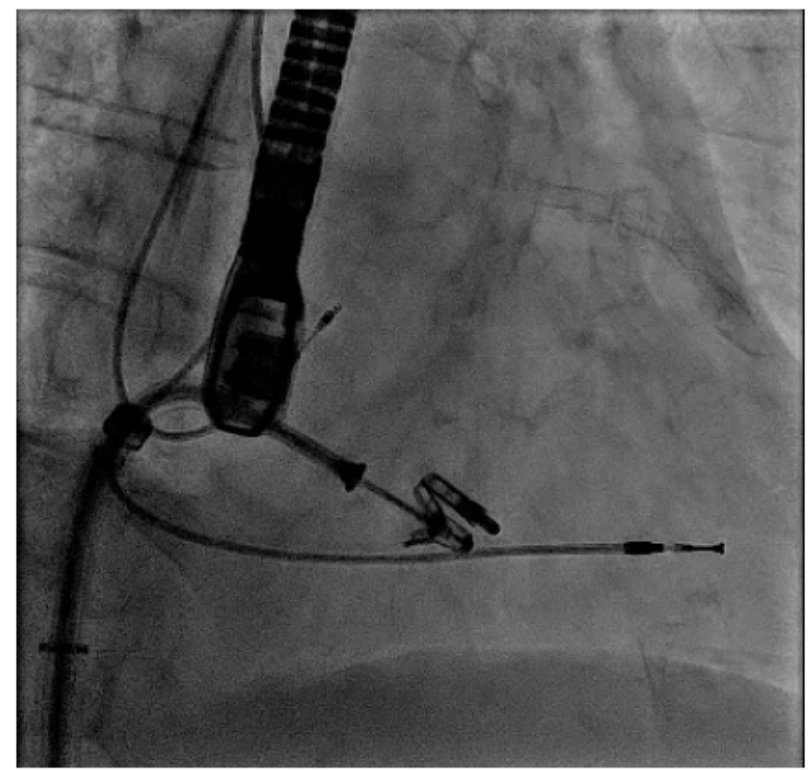

Figure 2. Intra-procedural imaging of the MitraClip $\AA$ device (Abbott Vascular, Santa Clara, CA, USA).

locked at the subclavian region.

To date, seven patients treated with this device have been reported $^{29}$. Initial first-in-man experience shows that the device was correctly implanted in all patients without any complication. There was no in-hospital mortality, and all of the treated patients completed 30-day follow-up without further evidence of device-related complication. A reduction in the severity of TR was observed in all patients as assessed by transthoracic 
echocardiography. This change in TR was associated with a significant improvement in New York Heart Association (NYHA) functional classification, accompanied by relevant reductions in peripheral edema in all patients. The clinical outcomes (up to 1 year) of the first 18 patients have been reported recently ${ }^{30}$. Acute TR reduction of at least one grade was achieved in $89 \%$ patients, with an extremely low incidence of adverse events. Significant improvements in functional status and reverse remodeling of the RV were observed at follow-up. An early feasibility trial is currently ongoing in the United States (NCT02471807).

\section{Results}

All of the above-mentioned percutaneous techniques have emerged during the last few years with the purpose of treating patients with severe symptomatic functional TR, who conventionally represent a high-risk surgical population. Most of the patients percutaneously treated today are affected by end-stage heart failure, with right ventricular dysfunction and severe comorbidities, and these therapeutic options are offered in a compassionate treatment scenario. In light of this, assessing the real clinical benefits of trans-catheter tricuspid valve therapies remains extremely difficult, as well as identifying which patients may benefit from an interventional treatment.

In order to address these issues, the first international registry for trans-catheter tricuspid valve therapies (the international multicenter TriValve registry) was established to collect data regarding patients undergoing tricuspid valve interventions with currently available devices ${ }^{31}$. To date, the TriValve registry has data from 106 patients with severe TR from 11 cardiac centers. Functional TR was present in $95.2 \%$ of patients, with a mean tricuspid annulus of $45.4 \pm 11 \mathrm{~mm}$. In $56.3 \%$ of patients, there was right ventricular dysfunction defined as TAPSE $<17$ $\mathrm{mm}$ and $95 \%$ of the entire cohort were in NYHA functional class III to IV. A total of $35 \%$ of patients had prior left heart valve intervention.

A total of $55 \%$ of patients $(\mathrm{n}=58)$ were treated by MitraClip, $16 \%$ by Trialign $(\mathrm{n}=17), 14 \%$ by TriCinch $(\mathrm{n}=15), 7 \%$ by FORMA $(n=7), 5 \%$ by Cardioband $(n=5)$, and $3 \%$ of patients
( $n=3$ ) underwent CAVI. No differences in terms of EURO-Score II and degree of right ventricular dysfunction were observed between the patients treated with the different techniques.

Procedural success was achieved in $62 \%$ of cases. At 30-day follow-up, all-cause mortality was $3.7 \%$, with an overall incidence of major adverse cardiac and cerebrovascular events of $26 \% ; 58 \%$ of patients were NYHA functional class I or II at 30 days. The dosage of diuretics was significantly reduced at follow-up compared to baseline, as was the degree of TR $(\leq 2+$ in $49 \%$ of patients).

These initial results showed that the multiple percutaneous devices available for the treatment of TR are being utilized in patients at high surgical risk with early clinical efficacy, but further studies are necessary to better define optimal patient selection, timing of intervention, disease severity, and device efficacy $^{31}$.

\section{Reporting outcomes after trans-catheter tricuspid valve therapies: towards T-VARC}

The analysis of preliminary results from the early feasibility trials with the different devices raises the issue of how to report outcomes after trans-catheter tricuspid valve therapies. Patients consistently report improvements in quality of life measures despite only modest reductions in TR, according to the conventional definitions. Given the discordance between TR reduction and clinical improvement, it is evident that we cannot use the definitions of procedural success for the tricuspid valve that are used for aortic and mitral valves. This observation raises the need to define appropriate outcomes in this patient population and develop standard definitions on how to evaluate and report outcomes.

\section{Competing interests}

The authors declare that they have no competing interests.

\section{Grant information}

The author(s) declared that no grants were involved in supporting this work.
1. Singh JP, Evans JC, Levy D, et al.: Prevalence and clinical determinants of mitral, tricuspid, and aortic regurgitation (the Framingham Heart Study). Am J Cardiol. 1999; 83(6): 897-902. PubMed Abstract | Publisher Full Text

2. Stuge O, Liddicoat J: Emerging opportunities for cardiac surgeons within structural heart disease. J Thorac Cardiovasc Surg. 2006; 132(6): 1258-61. PubMed Abstract | Publisher Full Text

3. F Nath J, Foster E, Heidenreich PA: Impact of tricuspid regurgitation on longterm survival. J Am Coll Cardiol. 2004; 43(3): 405-9. PubMed Abstract | Publisher Full Text | F1000 Recommendation

4. De Bonis M, Taramasso M, Lapenna E, et al.: Management of tricuspid regurgitation. F1000Prime Rep. 2014; 6: 58. PubMed Abstract | Publisher Full Text | Free Full Text
5. F Leviner DB, Medalion B, Baruch I, et al.: Tricuspid valve replacement: the effect of gender on operative results. J Heart Valve Dis. 2014; 23(2): 209-15. PubMed Abstract | F1000 Recommendation

6. Buzzatti N, laci G, Taramasso M, et al:: Long-term outcomes of tricuspid valve replacement after previous left-side heart surgery. Eur J Cardiothorac Surg. 2014; 46(4): 713-9; discussion 719. PubMed Abstract | Publisher Full Text

7. Rodés-Cabau J, Taramasso M, O'Gara PT: Diagnosis and treatment of tricuspid valve disease: current and future perspectives. Lancet. 2016; 388(10058): 243142. PubMed Abstract | Publisher Full Text

8. Taramasso $\mathrm{M}$, Vanermen $\mathrm{H}$, Maisano $\mathrm{F}$, et al.: The growing clinical importance of secondary tricuspid regurgitation. J Am Coll Cardiol. 2012; 59(8): 703-10. PubMed Abstract | Publisher Full Text 
9. Kim JB, Spevack DM, Tunick PA, et al:: The effect of transvenous pacemaker and implantable cardioverter defibrillator lead placement on tricuspid valve function: an observational study. J Am Soc Echocardiogr. 2008; 21(3): 284-7. PubMed Abstract | Publisher Full Text

10. Lancellotti P, Moura L, Pierard LA, et al:: European Association of Echocardiography recommendations for the assessment of valvular regurgitation. Part 2: mitral and tricuspid regurgitation (native valve disease). Eur J Echocardiogr. 2010; 11(4): 307-32. PubMed Abstract | Publisher Full Text

11. F Baumgartner H, Falk V, Bax JJ, et al:: 2017 ESC/EACTS Guidelines for the management of valvular heart disease. Eur Heart J. 2017; 38(36): 2739-91. PubMed Abstract | Publisher Full Text | F1000 Recommendation

12. $\mathrm{F}$ Lang RM, Badano LP, Tsang W, et al.: EAE/ASE recommendations for image acquisition and display using three-dimensional echocardiography. J Am Soc Echocardiogr. 2012; 25(1): 3-46. PubMed Abstract | Publisher Full Text | F1000 Recommendation

13. F Saremi F, Hassani C, Millan-Nunez V, et al:: Imaging Evaluation of Tricuspic Valve: Analysis of Morphology and Function With CT and MRI. AJR Am J Roentgenol. 2015; 204(5): W531-42. PubMed Abstract | Publisher Full Text | F1000 Recommendation

14. F Rodés-Cabau J, Hahn RT, Latib A, et al.: Transcatheter Therapies for Treating Tricuspid Regurgitation. J Am Coll Cardiol. 2016; 67(15): 1829-45. PubMed Abstract | Publisher Full Text | F1000 Recommendation

15. https://www.navigatecsi.com/technology

16. Lauten A, Ferrari M, Hekmat $\mathrm{K}$, et al.: Heterotopic transcatheter tricuspid valve implantation: first-in-man application of a novel approach to tricuspid regurgitation. Eur Heart J. 2011; 32(10): 1207-13. PubMed Abstract | Publisher Full Text | Free Full Text

17. F Lauten A, Doenst T, Hamadanchi A, et al.: Percutaneous bicaval valve implantation for transcatheter treatment of tricuspid regurgitation: clinical observations and 12-month follow-up. Circ Cardiovasc Interv. 2014; 7(2): 268-72. PubMed Abstract | Publisher Full Text | F1000 Recommendation

18. F Laule M, Stangl V, Sanad W, et al.: Percutaneous transfemoral management of severe secondary tricuspid regurgitation with Edwards Sapien XT bioprosthesis: first-in-man experience. J Am Coll Cardiol. 2013; 61(18): 1929-31. PubMed Abstract | Publisher Full Text | F1000 Recommendation

19. Kay JH, Maselli-Campagna G, Tsuji KK: Surgical Treatment of Tricuspid
Insufficiency. Ann Surg. 1965; 162(1): 53-8.

PubMed Abstract | Free Full Text

20. F Schofer J, Bijuklic K, Tiburtius C, et al:: First-in-human transcatheter tricuspid valve repair in a patient with severely regurgitant tricuspid valve. $J$ Am Coll Cardiol. 2015; 65(12): 1190-5

PubMed Abstract | Publisher Full Text | F1000 Recommendation

21. F Hahn RT, Meduri CU, Davidson CJ, et al: Early Feasibility Study of a Transcatheter Tricuspid Valve Annuloplasty: SCOUT Trial 30-Day Results. J Am Coll Cardiol. 2017; 69(14): 1795-806.

PubMed Abstract | Publisher Full Text | F1000 Recommendation

22. Taramasso M, Latib A, Denti $P$, et al.: Percutaneous repair of the tricuspid valv using a novel cinching device: acute and chronic experience in a preclinical large animal model. Eurolntervention. 2016; 12(7): 918-25. PubMed Abstract | Publisher Full Text

23. Latib A, Agricola E, Pozzoli A, et al.: First-in-Man Implantation of a Tricuspid Annular Remodeling Device for Functional Tricuspid Regurgitation. JACC Cardiovasc Interv. 2015; 8(13): e211-4.

PubMed Abstract | Publisher Full Text

24. Denti P: EuroPCR 2017, Paris.

25. Kuck KH: EuroPCR 2017, Paris.

26. Rogers J: TVT 2017, Chicago.

27. F Braun D, Nabauer M, Orban M, et al:: Transcatheter treatment of severe tricuspid regurgitation using the edge-to-edge repair technique. Eurolntervention. 2017; 12(15): e1837-e1844. PubMed Abstract | Publisher Full Text | F1000 Recommendation

28. Nickenig G, Kowalski M, Hausleiter J, et al: Transcatheter Treatment of Severe Tricuspid Regurgitation With the Edge-to-Edge MitraClip Technique. Circulation. 2017; 135(19): 1802-14. PubMed Abstract | Publisher Full Text

29. F Campelo-Parada F, Perlman G, Philippon F, et al:: First-in-Man Experience of a Novel Transcatheter Repair System for Treating Severe Tricuspid Regurgitation. J Am Coll Cardiol. 2015; 66(22): 2475-83. PubMed Abstract | Publisher Full Text | F1000 Recommendation

30. Perlman G: EuroPCR. 2017, Paris

31. Taramasso M, Hahn RT, Alessandrini $\mathrm{H}$, et al.: The International Multicenter TriValve Registry: Which Patients Are Undergoing Transcatheter Tricuspid Repair? JACC Cardiovasc Interv. 2017; 10(19): 1982-90.

PubMed Abstract | Publisher Full Text 


\section{Open Peer Review}

\section{Current Peer Review Status:}

\section{Editorial Note on the Review Process}

Faculty Reviews are review articles written by the prestigious Members of Faculty Opinions. The articles are commissioned and peer reviewed before publication to ensure that the final, published version is comprehensive and accessible. The reviewers who approved the final version are listed with their names and affiliations.

\section{The reviewers who approved this article are:}

\section{Version 1}

\section{Luigi Paolo Badano}

Department of Cardiac, Thoracic and Vascular Sciences, University of Padua, Padua, Italy Competing Interests: No competing interests were disclosed.

\section{Meindert Palmen}

Department of Cardiothoracic Surgery, Leiden University Medical Center, Leiden, The Netherlands

Competing Interests: No competing interests were disclosed.

\section{Gianfranco Butera}

Department of Congenital Cardiology and Cardiac Surgery, IRCCS Policlinico San Donato, San Donato Milanese, Italy

Competing Interests: No competing interests were disclosed.

The benefits of publishing with F1000Research:

- Your article is published within days, with no editorial bias

- You can publish traditional articles, null/negative results, case reports, data notes and more

- The peer review process is transparent and collaborative

- Your article is indexed in PubMed after passing peer review

- Dedicated customer support at every stage

For pre-submission enquiries, contact research@f1000.com 